\title{
Effects of occupational sunlight exposure and monsoon season on vitamin $D$ concentration among outdoor and indoor workers in Malaysia
}

\author{
Norliyana Aris ${ }^{1,2}$, Amal K. Mitra ${ }^{3}$, Wan Mohd Izani Bin Wan Mohamed ${ }^{4}$, Wan \\ Abdul Manan Bin Wan Muda ${ }^{5}$ \& Hamid Jan Bin Jan Mohamed ${ }^{*}$ \\ ${ }^{1}$ Nutrition and Dietetics Programme, School of Health Sciences, Universiti Sains \\ Malaysia, 16150 Kubang Kerian, Kelantan, Malaysia; ${ }^{2}$ Faculty of Food Science and \\ Nutrition, Universiti Malaysia Sabah, Jalan UMS, 88400 Kota Kinabalu, Sabah, \\ Malaysia; ${ }^{3}$ Department of Epidemiology \& Biostatistics, School of Public Health, \\ Jackson State University, Jackson, MS 39213, USA; ${ }^{4}$ Department of Medicine, School \\ of Medical Sciences, Universiti Sains Malaysia, 16150 Kubang Kerian, Kelantan, \\ Malaysia; ${ }^{5}$ Khazanah Research Institute, Level 25, Mercu UEM, Jalan Stesen Sentral \\ 5, 50470, Kuala Lumpur, Malaysia.
}

\begin{abstract}
Introduction: Despite abundant sunshine for cutaneous vitamin D synthesis, low levels of vitamin D have been documented among the Malaysian population. The aim of this study was to characterise the effects of occupational sunlight exposure and monsoon season on serum 25-hydroxyvitamin D [25(OH)D] concentration. Methods: A comparative cross-sectional study was performed among Malay outdoor $(n=119)$ and indoor workers $(n=119)$ in Kelantan. Two-point data were collected on the same participants, first during non-monsoon season and second during the northeast monsoon season. Data collection comprised of anthropometry measurements (body mass index and body fat), fasting blood test [serum 25(OH)D concentration], and questionnaire (physical activity level, sun exposure, sun protection use, and vitamin D intake). Vitamin D classification was based on the 2011 Endocrine Society Clinical Practice Guidelines. Results: This study found that serum 25(OH)D concentrations were significantly higher in outdoor compared to indoor workers irrespective of season $(p<0.001)$ and sex $(p<0.001)$. Monsoonal differences in serum 25(OH)D concentration was only observed in male outdoor workers (mean difference $=10.39$ $\mathrm{nmol} / 1, p<0.001)$. Significant association between vitamin D status and occupation was also observed $(p<0.001)$. However, no significant association was found between vitamin D status and monsoon season $\left[\chi^{2}(1)=0.076, p=0.783\right]$. Conclusion: Seasonal and occupational factors should be considered while evaluating individual serum $25(\mathrm{OH}) \mathrm{D}$ concentration and in comparing community studies, especially among workers.
\end{abstract}

Keywords: 25-hydroxyvitamin D, occupation, monsoon, sunlight exposure

\section{INTRODUCTION}

Known as the 'sunshine vitamin', sunlight exposure is a major and natural source of vitamin D. Although vitamin $\mathrm{D}$ can be obtained from the diet (foods or supplements), skin exposure to solar ultraviolet $B$ (UVB) radiation (wavelength

\footnotetext{
*Corresponding author: Prof Dr Hamid Jan Bin Jan Mohamed

Nutrition and Dietetics Programme, School of Health Sciences, Universiti Sains Malaysia, 16150 Kubang Kerian, Kelantan, Malaysia

Tel: (6)(09)7677618; Fax: (6)(09)7677515; E-mail: hamidjan@usm.my

doi: https://doi.org/10.31246/mjn-2020-0038
} 
290-315 nm) covers $90 \%$ of vitamin D production in humans (Holick, 2010). Therefore, any factors that prevent UVB radiation will reduce the cutaneous synthesis of vitamin D. Endogenous (e.g. skin pigmentation and thickness) and exogenous factors such as latitude, season, time of day, pollution, weather condition, and lifestyle (use of sunscreen, clothing, and indoor living) influence the cutaneous synthesis of vitamin D (Holick, 2010).

Vitamin D deficiency (as reflected by circulating serum 25-hydroxyvitamin D [25(OH)D] levels <50 nmol/1 or 20ng/ $\mathrm{ml}$ ) is a global health problem affecting all age groups, even in low latitude countries where there is abundant UVB rays for cutaneous vitamin $D$ synthesis, or in industrialised countries where fortification of foods with vitamin $D$ has been implemented (Palacios \& Gonzalez, 2014). In Malaysia, despite its close proximity to the equator and plentiful sunlight, high prevalence of vitamin $D$ deficiency has been reported in adults (Chin et al., 2014; Moy, 2011).

The relationship of vitamin D with occupation and season has been investigated. (Azizi et al., 2009; BargerLux \& Heaney, 2002; Cinar et al., 2014; Devgun et al., 1981; Vu et al., 2011). It has been demonstrated that some occupational groups such as indoor workers, shift workers, and healthcare workers are at a higher risk of vitamin D deficiency (Sowah et al., 2017). This risk will further accelerate during seasonal changes, especially in winter and spring (Cinar et al., 2014; Vu et al., 2011). To our knowledge, the effects of prolonged periods of rain during monsoon season on vitamin D levels are not well documented. Moreover, in Malaysia, the knowledge on the effects of different occupational groups on vitamin D levels is still scarce. Therefore, this study was conducted to characterise the effects of occupational sunlight exposure and monsoon season on serum 25(OH)D concentration among Malay workers during non-monsoon and monsoon season.

\section{MATERIALS AND METHODS}

\section{Study design, setting and participants}

A comparative cross-sectional study was conducted to compare the serum $25(\mathrm{OH}) \mathrm{D}$ concentration between outdoor and indoor workers in two different seasons (non-monsoon and monsoon). Outdoor workers were defined as those who experienced occupational sunlight exposure for $>2$ hours/day between 8.00 am to $2.00 \mathrm{pm}$ (Azizi et al., 2009), while indoor workers were those who stayed indoors more than half of their working hours. Based on this definition, fishermen and office staffs were assigned as outdoor and indoor workers, respectively. Malay workers were recruited for this study as Malays are the largest (>90\%) ethnic group in Kelantan. Workers were eligible for inclusion in the study if they were apparently healthy, aged 20 - 50 years, and fulfilled the definition of outdoor and indoor workers. Exclusion criteria included any major illnesses including diseases of the liver, kidney or thyroid, and if they were pregnant and/or lactating. Purposive sampling was adopted to ensure that participants were recruited from the two groups of interest (outdoor versus indoor workers). The study protocol was approved by the Human Research Ethics Committee, Universiti Sains Malaysia [USMKK/ PPP/JEPeM 247.3(10)], and a written informed consent was obtained from each subject before the study. Figure 1 shows the flowchart of the study.

\section{Study location}

Data collection for indoor workers took place at the government buildings of Wisma Persekutuan Kota Bharu, which involved 16 departments including the National Registration Department, 


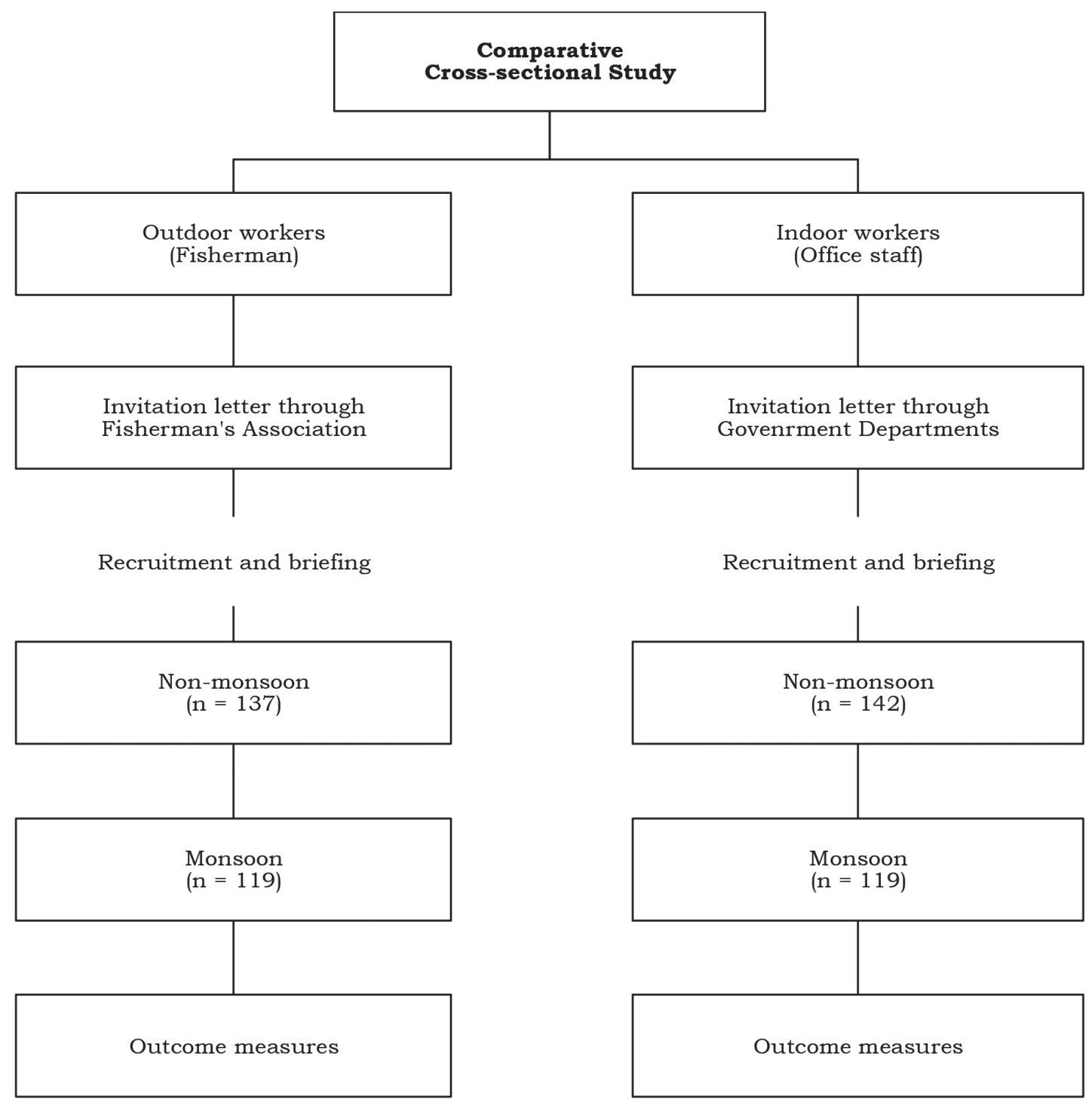

Figure 1. Flowchart of the study

Immigration Department, Department of Statistics, Valuation and Property Services Department, and Kelantan State Health Department. The Wisma Persekutuan was chosen because it is the only workplace with a high density of indoor working population in Kelantan. On the other hand, data collection for outdoor workers was conducted in four fishing villages namely Kampung Pantai Sabak (Kota Bharu District,
Latitude $6^{\circ} 7$ 'N), Kampung Pengkalan Petah (Bachok District, Latitude $6^{\circ} 4^{\prime} \mathrm{N}$ ), Kampung Kandis, and Kampung Pachakan (Pasir Puteh District, Latitude $\left.5^{\circ} 50 ’ \mathrm{~N}\right)$. These villages were located along the Peninsula's east coast and facing the South China Sea.

\section{Meteorological data}

Information on the northeast monsoon and weather forecasting were obtained 
from the Malaysia Meteorological Department (MMD). Samples collected during May to June 2012 represented the non-monsoon season, and those from January to February 2013 represented the northeast monsoon season. Data on environmental parameters such as temperature, relative humidity, and total rainfall for both non-monsoon and monsoon seasons were recorded at the Kota Bharu Meteorological Station (Latitude $6^{\circ} 10^{\prime} \mathrm{N}$ ), and were retrieved from the National Weather Centre. Additionally, for monsoon season, the weather was also observed physically in order to get the precise time for data collection. Since the half-life of serum vitamin $\mathrm{D}$ concentration is approximately 15 days (Holick, 2010), data collection was conducted three weeks after a continuous rainfall.

\section{Serum 25(OH)D concentration}

Vitamin D status was determined by measuringserum 25(OH)Dconcentration, as it is considered the robust "gold standard" method. To measure serum $25(\mathrm{OH}) \mathrm{D}$ concentration, a series of two fasting venous blood samples ( $5 \mathrm{~mL}$ each) were collected from each participant, measured by electrochemiluminescence immunoassay (ECLIA) on the Cobas e411 analyser (Roche Diagnostic, Switzerland) with Elecsys ${ }^{\circledR}$ Vitamin D Total Kit (REF: 05894913 190, Roche Diagnostic, Switzerland). The inter- and intra-assay coefficients of variation were $4.2 \%$ and $6.6 \%$, respectively. Vitamin $D$ status was in accordance with the U.S. Endocrine Society Clinical Practice Guideline 2011, with classifications as follows: sufficient (serum 25(OH)D concentration $\geq 75 \mathrm{nmol} / \mathrm{l}$ ), insufficient (serum 25(OH)D concentration $50-74$ $\mathrm{nmol} / 1$ ), and deficient (serum 25(OH)D concentration $<50 \mathrm{nmol} / 1)$.

\section{Anthropometric measurements}

Anthropometric measurements performed at each time point in the morning by two trained enumerators, which included height, weight, and body fat. Standardised techniques and the same equipments were used for all measurements. Measurements were taken in duplicate and the average was recorded. Height was measured with subjects barefooted, using a mechanical measuring tape (Seca 206, Hamburg, Germany) to the nearest $0.1 \mathrm{~cm}$. Body weight and body fat were measured using a total body composition analyser (Tanita SC-331S, Japan). Weight was recorded to the nearest $0.1 \mathrm{~kg}$ with subjects in light clothing and no shoes. Body mass index (BMI) was calculated as the ratio of weight in kilogram to the square of height in meters $\left(\mathrm{kg} / \mathrm{m}^{2}\right)$. Participants were categorised into the following World Health Organization (WHO) BMI classification: underweight, $<18.5 \mathrm{~kg} / \mathrm{m}^{2}$; normal, $18.5-24.9 \mathrm{~kg} /$ $\mathrm{m}^{2}$; overweight, $25.0-29.9 \mathrm{~kg} / \mathrm{m}^{2}$, and obese, $\geq 30 \mathrm{~kg} / \mathrm{m}^{2}$. Body fat measurement was based on the bioelectrical impedance analysis (BIA) technique. Percentage body fat was classified as follows: (1) acceptable range, with body fat between $6 \%-24 \%$ in male and 9\%-31\% in female; (2) unhealthy range (too high), with body fat $\geq 25 \%$ in male and $\geq 32 \%$ in female (Nieman, 2003).

\section{Sun exposure and sun protection assessment}

Sun exposure was estimated using a questionnaire adopted from Moy (2011). The workers were interviewed about their exposure to direct sunlight, which included the type, frequency, and duration (in minutes per day in a week) of outdoor activities. Besides, the participants were asked about their sun protection measures, such as wearing of long sleeves, long skirt, long pants, veils, hat/cap, gloves, and the use of sun block lotion and an umbrella. Sun exposure score was calculated by 
multiplying the duration (in minutes) of sun exposure per day with the number of days per week, whereas sun protection score was calculated by the total usage of sun protection and protective clothing $($ maximum $=8$, minimum $=0)$.

\section{Physical activity level}

The short version of the Malay International Physical Activity Questionnaire (IPAQ) was used to estimate participants' physical activity levels. IPAQ measures the specific types of activity that are vigorous-intensity, moderate-intensity, and walking for the past seven days. Participants were asked about the frequency (days) and duration per day (in minutes) per week for each specific type of activity. Recorded data were then analysed using the Excel spreadsheet, following the IPAQ's guidelines for data processing and analysis (IPAQ Group, 2005). Physical activity was expressed as a continuous score (Total MET-minute/week) and physical activity level (high, moderate and low).

\section{Vitamin D intake}

Vitamin D intakes of participants were assessed using a food frequency questionnaire (FFQ) provided and adapted from Wu et al. (2009). The modified version consisted of 30 foods with ten response options ranging from 'never or $<1$ per month' to '>2 times per day' for the frequency of consumption. The serving sizes were based on household measurements (e.g. cups, spoons) and natural units (e.g. 1 slice). Participants were asked to rank serving sizes as medium (standard portion size), small (half of medium), or large (twice medium). The amount of vitamin D from foods were analysed using the Nutritionist Pro $^{\mathrm{TM}}$ Diet Analysis software (Axxya Systems LLC., USA) based on the U.S. Department of Agriculture (USDA) Foods database. The amount of vitamin
D intake was calculated from the FFQ according to the following formula: participant's frequency of intake $\times$ amount of the item consumed (calculated as 0.5 for smaller than average serving size, and 1.5 for larger than average serving size) $\times$ amount of nutrient in the serving size indicated.

\section{Statistical analysis}

Statistical analysis was performed using the IBM SPSS Statistics for Windows, Version 23.0 (Armonk, NY: IBM Corp.). Descriptive analysis was performed to describe the basic features of the data. Data were presented according to occupation (outdoor and indoor), season (non-monsoon and monsoon), and sex (male and female). Categorical variables were presented as frequency (percentages), while numerical variables were presented as mean and standard deviation (SD) for normally distributed data, or median and inter-quartile range $(\mathrm{Q} 1, \mathrm{Q} 3)$ for skewed data. In order to compare the environmental characteristics and other parameters between outdoor and indoor groups or males and females, the independentsample $t$-test or Mann-Whitney test was conducted for continuous variables. Within each study group, the differences in study variables of monsoon and nonmonsoon seasons were assessed by paired-sample $t$-test or Wilcoxon Signed Rank test depending on the distribution of the data. Chi-square test was performed for categorical data to test for the associations between (i) vitamin D status and occupation; (ii) vitamin D status and sex; (iii) vitamin D status and season. For this analysis, vitamin D status was re-grouped into two categories (sufficient and insufficient), in order to fulfil the assumption of chi-square analysis. This was done by combining the vitamin $\mathrm{D}$ deficient and insufficient groups together. All analyses conducted were two-tailed, and a $p$-value 


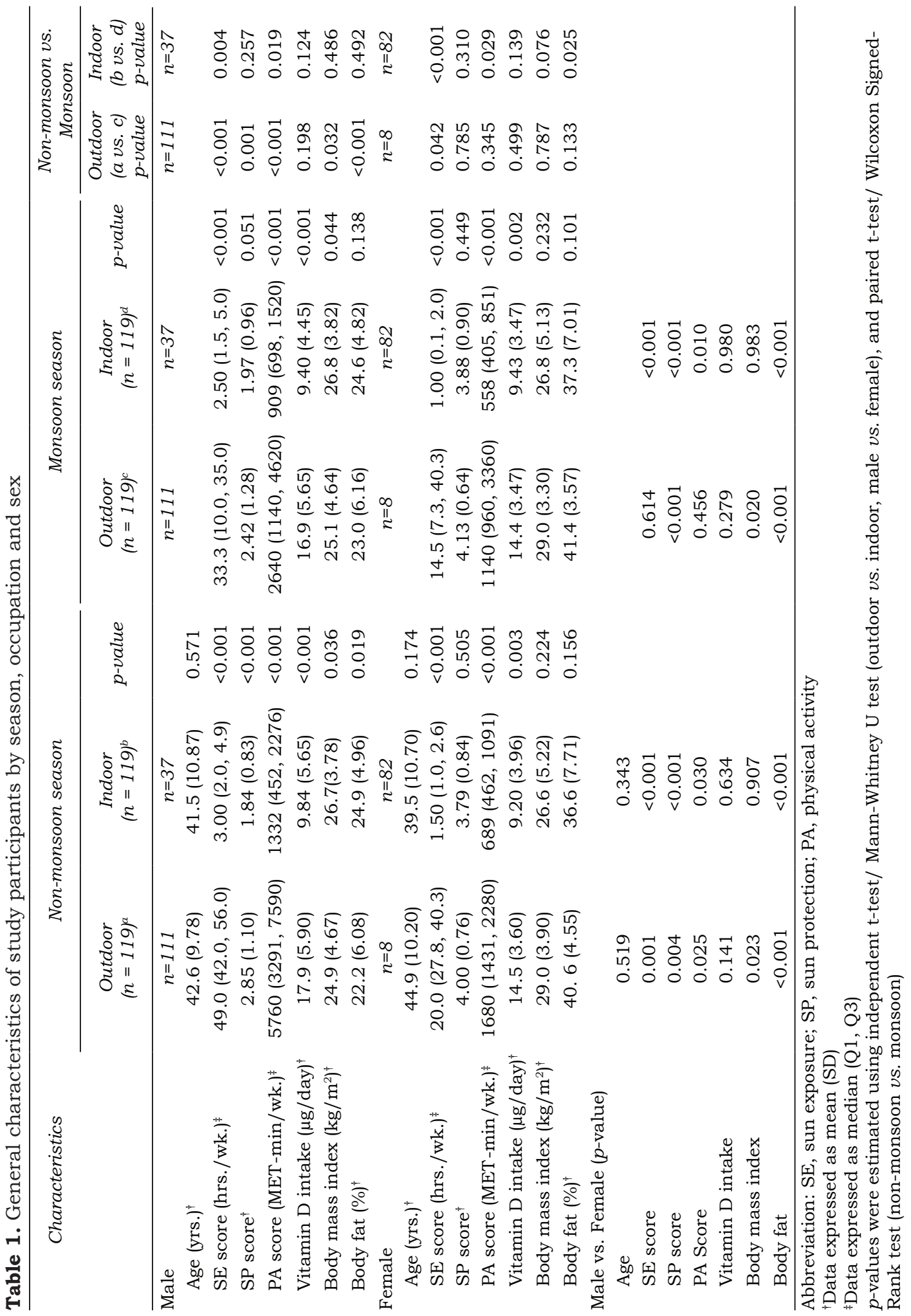


of $\leq 0.05$ was considered as statistically significant.

\section{RESULTS}

The study recruited 279 healthy workers, of which 137 (49.0\%) were outdoor workers and 142 (51.0\%) were indoor workers. Forty-one subjects (14.7\%) were dropped because of incomplete data, and 238 (85.0\%) qualified for the analysis. The number of people who remained in the analysis was similar in the two groups (119 per group). Participants were all Muslims.

Figure 2 illustrates the patterns of average rainfall, relative humidity, and daily temperature during the months of monsoon and non-monsoon seasons. The warmest months were May and June, while most rainfalls occurred in December. As expected, the environmental parameters changed significantly from non-monsoon to monsoon season. Daily temperature decreased by $1.3^{\circ} \mathrm{C}$ during monsoon compared to non-monsoon season. Besides, there were increments of $6.23 \%$ in relative humidity and rainfall by $240 \%$ during the monsoon season, compared with the non-monsoon season.

Table 1 shows the general characteristics of the participants. The mean age for outdoor and indoor workers were $42.75 \pm 9.78$ and $40.11 \pm 10.74$ years, respectively. Comparisons between outdoor and indoor workers revealed that outdoor workers had significantly higher sunlight exposure, physical activity, and vitamin D intake than indoor workers regardless of sex and season. Sun protection score was significantly higher in male outdoor workers than male indoor workers during non-monsoon season, but was similar during monsoon season. No significant difference was observed in sun protection score between female outdoor and indoor workers in both seasons. BMI and fat percentage

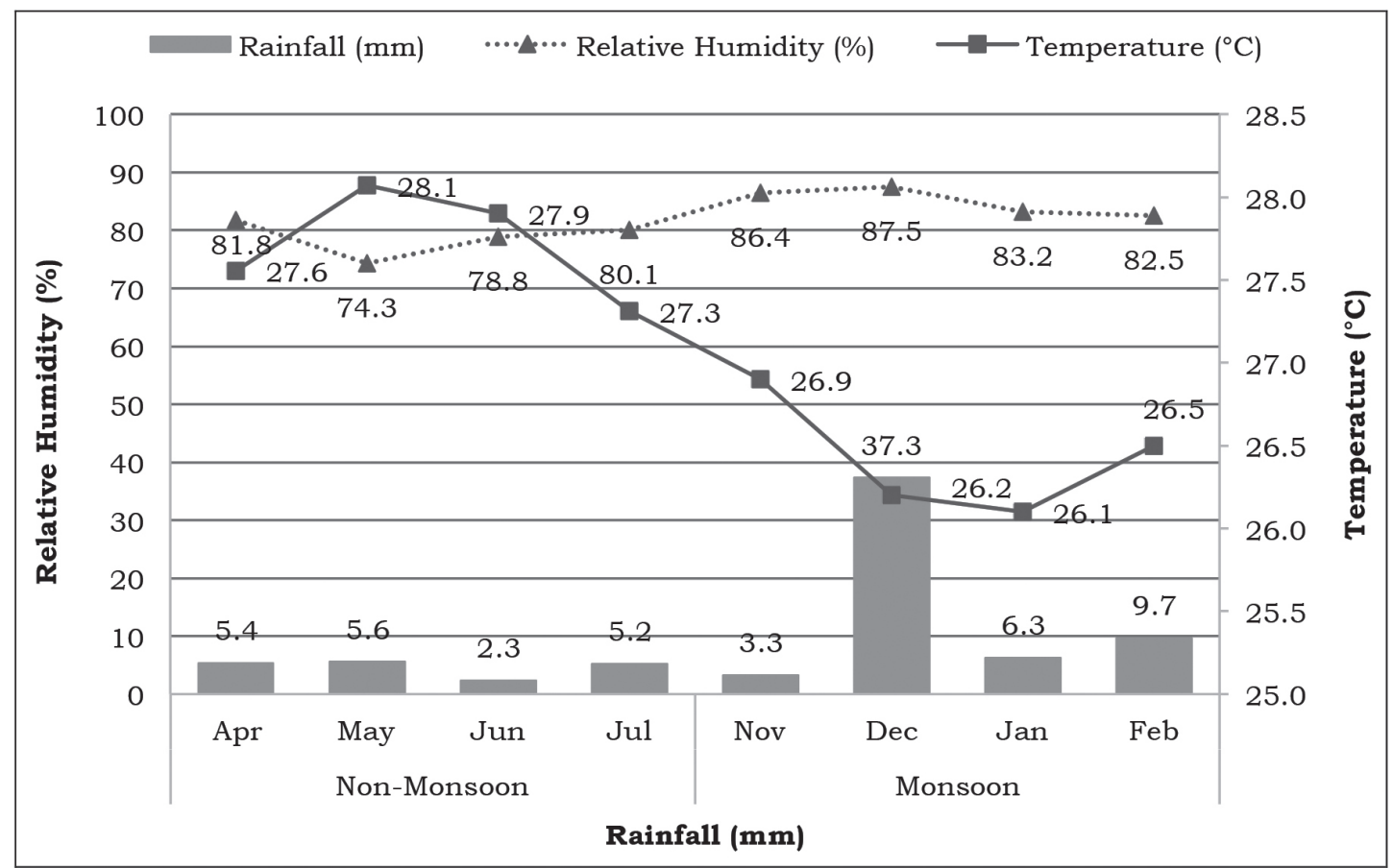

Figure 2. Average rainfall, relative humidity and 24 hours mean temperature during nonmonsoon and monsoon season 
(non-monsoon only) were significantly lower in outdoor than indoor workers. However, female workers of both groups showed similar BMI and fat percentage.

Monsoonal differences revealed that sun exposure and physical activity scores were significantly decreased from non-monsoon to monsoon season in all participants, while vitamin D intake and sun protection score remained similar in both seasons. But these changes were not observed in female outdoor workers for physical activity score $(p=0.345)$ and male outdoor workers for sun protection score $(p=0.001)$. Increased BMI and body fat were observed among outdoor workers. Both BMI and body fat remained unchanged in male indoor and female outdoor workers. Meanwhile, body fat but not BMI, increased significantly among female indoor workers from nonmonsoon to monsoon season.
Sex differences showed that male workers spent significantly more hours under the sunlight with lesser use of sun protection, and had higher physical activity in both occupations and seasons. However, in monsoon season, sunlight exposure and physical activity scores were equal between male and female outdoor workers. In terms of vitamin D intake, no significant differences were observed between male and female workers in both occupations and seasons. BMI (except in indoor workers) and body fat were significantly lower in male than female workers.

Figure 3 shows the distribution in the use of sun protection among male and female workers during non-monsoon season. Among male workers, the use of sun protection items included long pants, cap/hat, long sleeve, and gloves. On the other hand, veil, long sleeve,
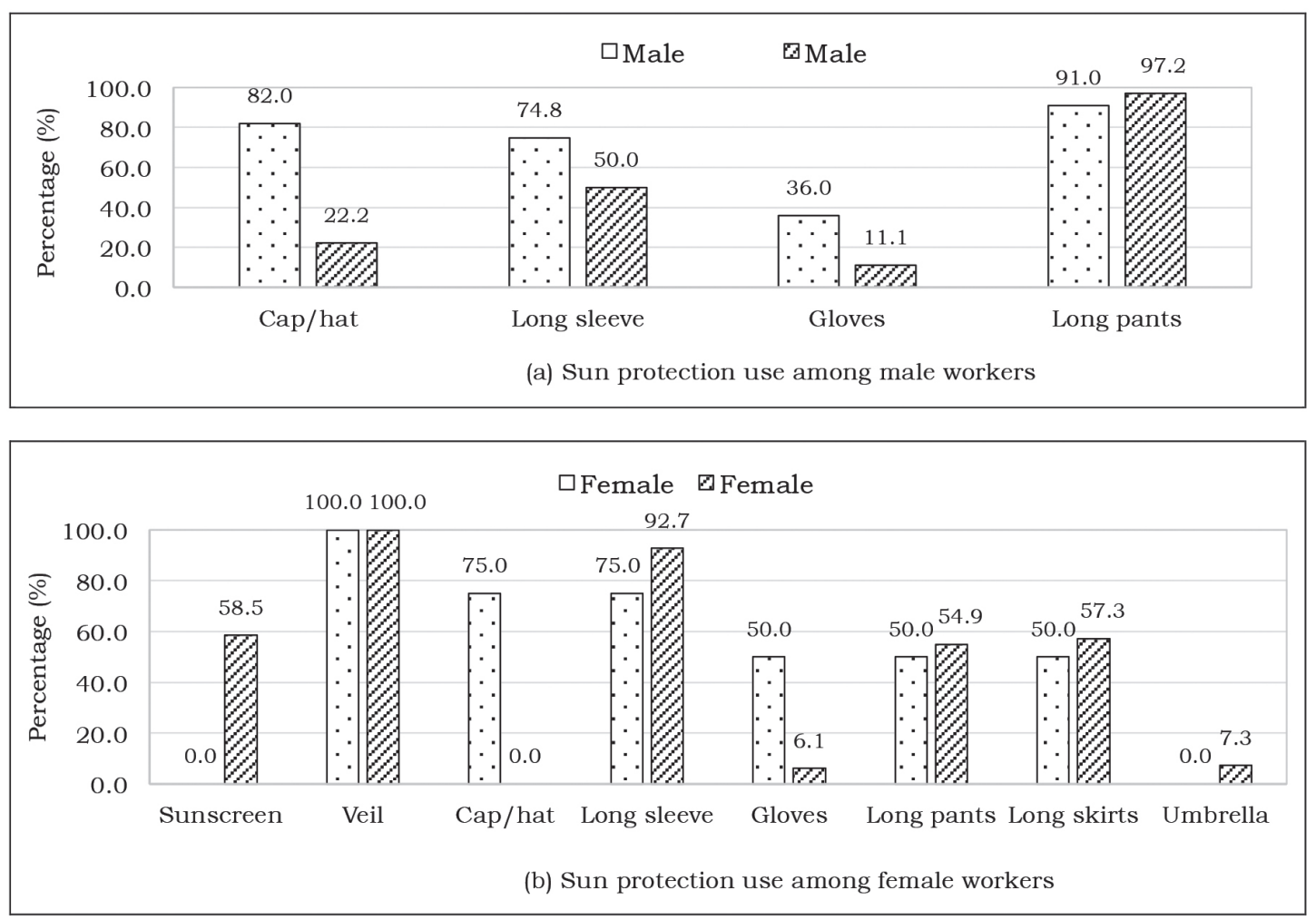

Figure 3. Distribution of sun protection use among male and female workers 
long pants, and long skirts were the most commonly used items by female workers. Only female indoor workers used sunscreen.

Table 2 provides the results of serum 25(OH)D concentration and vitamin $\mathrm{D}$ status according to season, occupation and sex. The results clearly demonstrated that serum 25(OH) D concentrations were significantly higher in outdoor workers compared to indoor workers irrespective of season and sex $\quad(p<0.001)$. Furthermore, serum $25(\mathrm{OH}) \mathrm{D}$ was significantly lower in females compared with their male counterparts $\quad(p<0.001)$ Significant seasonal (monsoon) difference in serum $25(\mathrm{OH}) \mathrm{D}$ concentration was only found in male outdoor workers $(p<0.001)$. The distribution of vitamin $\mathrm{D}$ status showed that majority of outdoor workers $(96.4 \%$ males and $62.5 \%$ females) had sufficient levels of vitamin D. Among indoor workers, majority of male and female workers were vitamin D insufficient and deficient, respectively. Chi-square tests revealed that whether in non-monsoon or monsoon season, there was a significant association between vitamin $\mathrm{D}$ status and occupation. Besides, a significant association between vitamin $D$ status and sex was also observed [non-monsoon, $\quad \chi^{2}(1)=123.2, \quad p<0.001$; monsoon, $\left.\quad \chi^{2}(1)=122.0, \quad p<0.001\right]$. However, no significant association was found between vitamin D status and season $\left[\chi^{2}(1)=0.076, p=0.783\right)$.

\section{DISCUSSION}

This study sought to determine the effects of occupation and season on serum 25(OH)D concentrations. The results of this comparative crosssectional study indicated that for both seasons, the $25(\mathrm{OH}) \mathrm{D}$ concentration of outdoor workers was about two-fold that of indoor workers. Furthermore, this study found a significant association between the type of occupation and vitamin $\mathrm{D}$ status. The results also showed that occupation such as indoor work was related to a higher prevalence of vitamin D insufficiency and deficiency. However, no significant association was found between season and vitamin D status.

\section{Occupation and vitamin D}

To the best of our knowledge, this is the first study to report the highest serum 25 $(\mathrm{OH}) \mathrm{D}$ concentration in Malaysian adults. The concentration observed among outdoor workers in this study was higher than that in Korean fishermen during summer with a mean of $59.3 \pm 22.2$ nmol/1 (Lee et al., 2018). Besides, lower serum 25(OH)D concentrations have also been reported among outdoor workers in Israel and India, which ranged between 57 and 74 nmol/1 (Azizi et al., 2009; Goswami et al., 2016). In fact, serum concentrations of 25(OH)D above 200 $\mathrm{nmol} / \mathrm{L}$ are not rare among healthy persons with ample sunlight exposure (Barger-Lux and Heaney, 2002). On the other hand, the concentrations of serum $25(\mathrm{OH}) \mathrm{D}$ in indoor workers were about the same as those of previous studies that have examined the relationship between occupation and vitamin D levels (Azizi et al., 2009; Cinar et al., 2014).

In this study, the different work environments between outdoor and indoor workers contributed to significant differences in sunlight exposure. Outdoor workers exposed themselves to the sunlight chronically and spent more than half of their day under sunlight, especially during peak hours of UVB radiation (10.30 a.m. and 3.30 p.m.). In contrast, indoor workers spent most of their day inside the building, hence exposure to sunlight was limited. As a major source of vitamin $\mathrm{D}$, sunlight exposure contributes $90 \%$ of vitamin $\mathrm{D}$ production in humans through cutaneous synthesis after solar UVB 


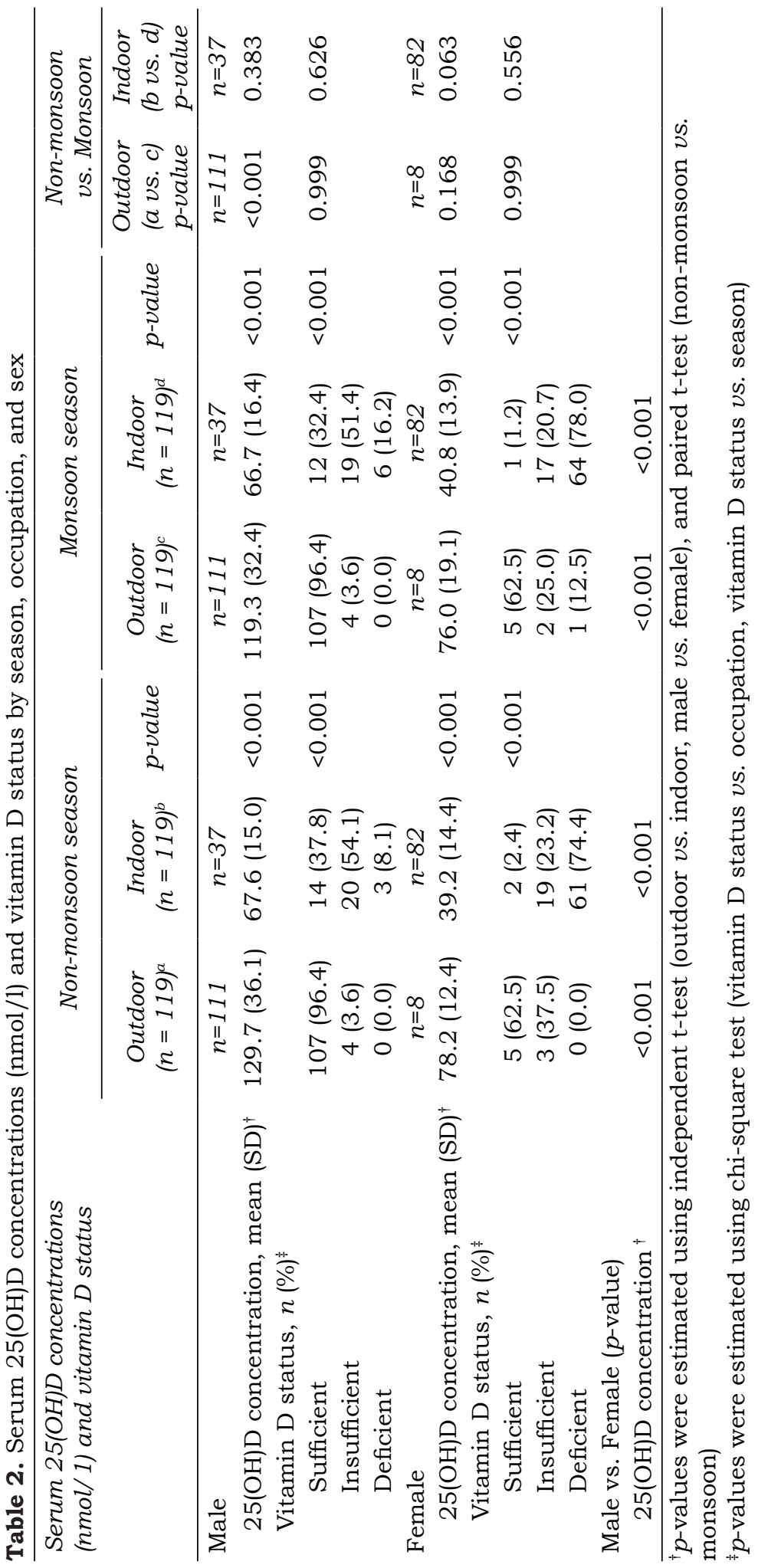


radiations (Holick, 2010). This factor best explains the difference in serum $25(\mathrm{OH})$ $\mathrm{D}$ concentrations between outdoor and indoor workers.

Another factor that contributed to the higher $25(\mathrm{OH}) \mathrm{D}$ concentrations in outdoor compared to indoor workers was a higher mean intake of vitamin $\mathrm{D}$ in outdoor than indoor workers. The mean daily vitamin $D$ intake in this study (>9.2 ug) was considerably higher than the levels observed in Malaysian athletes aged $\geq 18$ years from the National Sports Institute, that were based on food consumption only

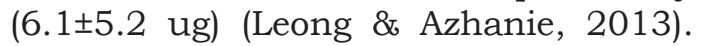
Majority of outdoor workers (60.5\%) achieved the daily recommended level of vitamin D intake (15 $\mu \mathrm{g} /$ day), but not so in the case of indoor workers (11.9\%). As fishermen (outdoor workers), seafood is their main food source (Coutinho et al., 2019). Fatty fish and eggs are major food sources of vitamin D. Lehmann et al. (2015) reported that fish consumption increased concentrations of serum 25(OH)D, although recommended fish intake cannot optimise vitamin D status. Other than supplements, dietary sources of vitamin D are limited. Therefore, skin synthesis of vitamin D by UVB rays remains an alternatively inexpensive source of vitamin D in humans (Coutinho et al., 2019).

The current study revealed that none of the outdoor workers were classified as vitamin $\mathrm{D}$ deficient (serum $25(\mathrm{OH}) \mathrm{D}$ $<50 \mathrm{nmol} / 1)$, except for $1(0.8 \%)$ female participant during the monsoon season. In contrast, more than half of the indoor workers (53.8\%, non-monsoon; $58.8 \%$, monsoon) were identified with vitamin D deficiency. High prevalence of vitamin $\mathrm{D}$ deficiency among indoor workers was due to long working hours that led to sunlight deprivation, hence reducing the cutaneous synthesis of vitamin D (Sowah et al., 2017). The study conducted among Israeli workers showed that indoor workers had four- to eight-folds lower occupational exposure to solar UVB than outdoor workers (Azizi et al., 2009). According to Godar (2005), indoor workers receive about 3\% of total annual available UV compared to $10 \%$ received by outdoor workers.

\section{Monsoon and vitamin $D$}

The present study is first of its kind in Malaysia to provide evidence with respect to the effects of monsoon season (also known as rainy season) on serum $25(\mathrm{OH}) \mathrm{D}$ concentrations. The monsoonal differences in serum $25(\mathrm{OH})$ $\mathrm{D}$ concentration was observed only in outdoor workers, despite the significant decrease in sunlight exposure scores for both groups during monsoon. However, the results of this study did not show any significant association between vitamin D status and season $(p=0.783)$, meaning there was no difference in the occurrence of vitamin D sufficiency/ insufficiency between non-monsoon and monsoon season.

The observed results of serum $25(\mathrm{OH}) \mathrm{D}$ concentration in indoor workers was similar to those reported in pregnant Thai women (18 to 45 years), which found no significant difference in serum 25(OH)D concentrations between rainy and winter season (Pratumvinit et al., 2015). Tangoh et al. (2018) also found that rainy or dry season had no significant effects on vitamin D level in non-pregnant participants $(\geq 35$ years) in Cameroon. In contrast, research conducted in countries with four seasons (summer, fall, winter, and spring) found that serum 25(OH)D concentrations were significantly affected by seasons (Azizi et al., 2009; Barger-Lux \& Heaney, 2002; Cinar et al., 2014; Devgun et al., 1981; Vu et al., 2011).

Another important finding was that outdoor workers showed higher serum 25(OH)D concentrations than indoor workers in both seasons. Similar results 
were reported in four seasons studies among Israeli (Azizi et al., 2009) and Scottish workers (Devgun et al., 1981), suggesting that despite seasonal changes on serum 25(OH)D concentrations, outdoor workers maintained the highest levels at all seasons. It is possible that in outdoor workers, occupational sunlight exposure lasted into monsoon, hence vitamin $\mathrm{D}$ synthesis continued from the de novo synthesis of vitamin $\mathrm{D}$ precursor (Devgun et al., 1981), which was produced and stored during the non-monsoon season.

The noticeable effect of monsoon on serum $25(\mathrm{OH}) \mathrm{D}$ concentration in male outdoor workers is best explained by the fact that monsoon weather affected fishing activities among workers. The northeast monsoon is described as a wet season that is associated with cloudy conditions and frequent afternoon showers. During monsoon season, four to five episodes of monsoon surges are expected. The monsoon surges bring a continuous, moderate to heavy rainfall lasting two to five days, occasionally windy conditions and a few days of cooler temperatures with unavailability of sunlight (MMD, 2017). During this period, participants of both groups were more likely to spend more time indoor based on the declining sunlight exposure and lesser physical activity. Strong winds, high wave and rough seas put outdoor workers off work and they stay indoor during this time. A local study has revealed that monsoon weather significantly affects fishing operation, with $75 \%$ of fisherman not being able to go to sea (Yaakob \& Chau, 2005). Lack of outdoor work during this time may explain the significant increase in body weight, BMI and body fat percentage in male outdoor workers.

Additionally, significant changes in weather conditions may also contribute to decreased serum $25(\mathrm{OH})$ $\mathrm{D}$ concentrations during monsoon in outdoor workers. Firstly, distribution of UV erythemal dose is strongly correlated with the monsoon seasons and atmospheric variables in Malaysia, which is highest in April (non-monsoon) and lowest in December (monsoon) (Tan et al., 2018). Secondly, a strong positive correlation has been observed between relative humidity and cloud cover (Walcek, 1994). At 80\% humidity, the average cloud cover is about $50 \%$. In this study, the relative humidity during monsoon was more than $80 \%$, for which the expected cloud cover was greater than $50 \%$. A cloud cover of more than $50 \%$ was found to significantly reduce UVB radiation (Németh et al., 1996) and thus, decreases the synthesis of pre-vitamin D3 by $20 \%$ on a cloudy day (Holick, 2010).

\section{Sex and vitamin $D$}

The current study found that female workers had lower serum $25(\mathrm{OH})$ $\mathrm{D}$ concentrations than male workers regardless of season and occupation. A high prevalence of vitamin $\mathrm{D}$ deficiency (74.4\%, non-monsoon; $78.8 \%$ monsoon) was observed among female indoor workers. The proportion of deficiency (serum 25(OH)D $<50 \mathrm{nmol} / \mathrm{L}$ ) reported in this study was lower compared to a study conducted among Malay women who were public university employees, with a prevalence of $86.9 \%$ (Moy 2011). More time spent in indoor and high sun protection measures among females are accounted for these findings. Moreover, avoiding the sun by using sunscreen and an umbrella contributed to the deficient level of serum 25(OH)D concentrations among female indoor workers. As a common practice in Muslim culture, the female participants dressed modestly which ranged from using a simple scarf/ veil to full body covering (except face), which limited skin exposure to sunlight (Moy, 2011). In this study, $100 \%$ of female workers wore a veil, and majority 
of them wore long clothes whenever they went outdoor. Previous studies have confirmed that vitamin $\mathrm{D}$ is negatively correlated with the Islamic dressing as part of culture influence (Shakir, 2012).

In addition, higher body fat might have contributed to lower serum $25(\mathrm{OH})$ $\mathrm{D}$ concentrations in female workers. This study showed that majority of the female workers were overweight/obese (87.5\% outdoor, $63.4 \%$ indoor), and had excessive body fat (100\% outdoor; $74.4 \%$ indoor). The inverse relationship between BMI and body fat with vitamin $\mathrm{D}$ has been conclusively shown (Chin et al., 2014; Touvier et al., 2014; Wortsman et al., 2000). As vitamin $\mathrm{D}$ is a fatsoluble vitamin, obesity enhances the uptake of vitamin D by adipose tissue. This causes synthesised vitamin $D$ to be trapped in the body fat compartment (adipose tissue), which results in lower bioavailability of serum 25(OH)D in the blood circulation (Wortsman et al., 2000).

In this study, both male and female outdoor workers had higher physical activity levels than indoor workers. It has been demonstrated that physical activity, as measured using various different tools, is associated with vitamin D level (Chin et al., 2014; Touvier et al., 2014). Higher physical activity level in outdoor than indoor workers was mainly because of the differences in occupational physical workloads, which involved heavy work, repetitive activities or forced static postures (BAuA, 2019). In a previous study, physical activity was often used as a surrogate for the amount of time spent outdoors. Therefore, participants who were physically active also tended to spend more time under the sun (Touvier et al., 2014).

One of the limitations of this study was the unavailability of solar UVB radiation data. The meteorological data collected and explored countered this limitation. Besides that, a small sample size of female outdoor workers, although common in this population, might have contributed to the non-significant monsoonal differences in serum $25(\mathrm{OH})$ $\mathrm{D}$ concentration among this population.

\section{CONCLUSION}

This study indicated that occupational sunlight exposure of serum $25(\mathrm{OH})$ $\mathrm{D}$ concentration was about two times greater in outdoor than indoor workers. A significant monsoon deficit of serum 25(OH)D concentration was observed only among outdoor workers. Regardless of season and occupation, female workers had significantly lower serum 25(OH) D concentrations than male workers. People should be advised to have more outdoor activities and sun exposure for getting an adequate level of vitamin D. Besides, seasonal and working environment should be considered while evaluating individual serum $25(\mathrm{OH})$ $\mathrm{D}$ concentration and when comparing community studies, especially among workers.

\section{Acknowledgement}

The vitamin D analysis kit was provided by Roche (Malaysia) Sdn. Bhd. The authors acknowledge Prof. Dr. Moy Foong Ming and Prof. Dr. Susan Whiting for their contributions by facilitating some of the research materials. This project was funded by a research grant from the Fundamental Research Grant Scheme (FRGS), Malaysia (203/ PPSK/6171141).

\section{Authors' contributions}

NA, conducted the study, data analysis and interpretation, prepared the draft of the manuscript and reviewed the manuscript; AKM, assisted in drafting of the manuscript and reviewed the manuscript; WMIBWM, medical advisor and reviewed the manuscript; WAMBWM, conceptualised and designed the study; HJBJM, principal investigator and reviewed the manuscript.

\section{Conflict of interest}

The author(s) declared no potential conflict of interest with respect to the research, authorship, and/or publication of this article. 


\section{References}

Azizi E, Pavlotsky F, Vered I \& Kudish AI (2009). Occupational exposure to solar UVB and seasonal monitoring of serum levels of 25-hydroxy vitamin D3: a case-control study. Photochem Photobiol 85(5):1240-1244.

Barger-Lux MJ \& Heaney RP (2002). Effects of above average summer sun exposure on serum 25-hydroxyvitamin D and calcium absorption. $J$ Clin Endocrinol Metab 87(11):4952-4956.

BAuA (2019). Physical Workload (Federal Institute for Occupational Safety and Health). From https://www.baua.de/EN/ Topics / Work-design / Physical-workload / functions/Publications-search_Formular. html?queryResultId=null\&pageNo=0 [Retrived Feb 2019].

Chin KY, Ima-Nirwana S, Ibrahim S, Mohamed IN \& Wan Ngah WZ (2014). Vitamin D status in Malaysian men and its associated factors. Nutrients 6(12):5419-5433.

Cinar N, Harmanci A, Yildiz BO \& Bayraktar M (2014). Vitamin D status and seasonal changes in plasma concentrations of 25-hydroxyvitamin D in office workers in Ankara, Turkey. Eur $J$ Intern Med 25(2):197-201.

Coutinho RCS, Santos AFD, Costa JGd \& Vanderlei AD (2019). Sun exposure, skin lesions and vitamin D production: evaluation in a population of fishermen. An Bras Dermatol 94(3):279-286.

Devgun MS, Paterson CR, Johnson BE \& Cohen C (1981). Vitamin D nutrition in relation to season and occupation. Am $J$ Clin Nutr 34(8)1501-1504.

Godar DE (2005). UV doses worldwide. Photochem Photobiol 81(4):736-749.

Goswami R, Saha S, Sreenivas V, Singh N \& Lakshmy R (2016). Vitamin D-binding protein, vitamin $\mathrm{D}$ status and serum bioavailable 25(OH)D of young Asian Indian males working in outdoor and indoor environments. J Bone Miner Metab 35(2):177-184.

Holick MF (2010). Vitamin D: Physiology, Molecular Biology, and Clinical Applications. Springer Science \& Business Media, New York.

IPAQ Group (2005). In: Guidelines for data processing and analysis of the International Physical Activity Questionnaire (IPAQ)-short and long forms. From https://sites.google. $\mathrm{com} / \mathrm{site} /$ theipaq/scoring-protocol [Retrieved January 22 2019].
Lee DH, Park KS \& Cho MC (2018). Laboratory confirmation of the effect of occupational sun exposure on serum 25-hydroxyvitamin D concentration. Medicine (Baltimore) 97(27):e11419.

Lehmann U, Gjessing HR, Hirche F, MuellerBelecke A, Gudbrandsen OA, Ueland PM, Mellgren G, Lauritzen L, Lindqvist H, Hansen AL, Erkkilä AT, Pot GK, Stangl GI \& Dierkes $J$ (2015). Efficacy of fish intake on vitamin D status: a meta-analysis of randomized controlled trials. Am J Clin Nutr 102(4):837847.

Leong L \& Azhanie AN (2013). Vitamin D Intake and Sun Exposure Among Malaysian Athletes in National Sports Institute, Bukit Jalil. Malaysian Journal of Medicine and Health Sciences 9(1):21-28.

Malaysia Meteorological Department, MMD (2017). Monsoon. Fromhttp://www.met.gov.my/ web / metmalaysia/education/weather / weatherphenomena/monsoon [Retrieved 4 January 2018].

Moy FM (2011). Vitamin D status and its associated factors of free-living Malay adults in a tropical country, Malaysia. $J$ Photochem Photobiol $B$ 104(3):444-448.

Németh P, Tóth Z \& Nagy Z (1996). Effect of weather conditions on UV-B radiation reaching the earth's surface. J Photochem Photobiol B 32(3):177-181.

Nieman DC (2003). Exercise testing and prescription: a health-related approach. McGraw-Hill New York.

Palacios C \& Gonzalez L (2014). Is vitamin $\mathrm{D}$ deficiency a major global public health problem? J Steroid Biochem Mol Biol 144(Pt A):138-145.

Pratumvinit B, Wongkrajang P, Wataganara T, Hanyongyuth S, Nimmannit A, Chatsiricharoenkul S, Manonukul K \& Reesukumal K (2015). Maternal vitamin D status and its related factors in pregnant women in Bangkok, Thailand. Plos One 10(7):e0131126.

Shakir DK (2012). In: Vitamin D deficiency and cultural influences among Muslim women in Southern Illinois. (Dissertation). Master of Science Degree, Southern Illinois University Carbondale. From https:// opensiuc.lib.siu.edu/cgi/viewcontent. cgi?article $=1963 \&$ context $=$ theses. $\quad$ [Retrieved 19 Oct 2018] 
Sowah D, Fan X, Dennett L, Hagtvedt R \& Straube S (2017). Vitamin D levels and deficiency with different occupations: a systematic review. BMC Public Health 17(1):519.

Tan KC, Lim HS \& Mat Jafri MZ (2018). Study on solar ultraviolet erythemal dose distribution over Peninsular Malaysia using Ozone Monitoring Instrument. The Egyptian Journal of Remote Sensing and Space Science 21(1):105110.

Tangoh DA, Apinjoh TO, Mahmood Y, Nyingchu RV, Tangunyi BA, Nji EN, Azhar A \& Achidi EA (2018). Vitamin D status and its associated risk factors among adults in the Southwest Region of Cameroon. J Nutr Metab 2018:47425744742574.

Touvier M, Deschasaux M, Montourcy M, Sutton A, Charnaux N, Kesse-Guyot E, Assmann KE, Fezeu L, Latino-Martel P, Druesne-Pecollo N, Guinot C, Latreille J, Malvy D, Galan P, Hercberg S, Le Clerc S, Souberbielle JC \& Ezzedine K (2014). Determinants of vitamin D status in Caucasian adults: influence of sun exposure, dietary intake, sociodemographic, lifestyle, anthropometric, and genetic factors. $J$ Invest Dermatol 135(2):378-388.
Vu LH, Whiteman DC, van der Pols JC, Kimlin MG \& Neale RE (2011). Serum vitamin D levels in office workers in a subtropical climate. Photochem Photobiol 87(3):714-720.

Walcek CJ (1994). Cloud Cover and Its Relationship to Relative Humidity during a Springtime Midlatitude Cyclone. Monthly Weather Review 122(6):1021-1035.

Wortsman J, Matsuoka LY, Chen TC, Lu Z \& Holick MF (2000). Decreased bioavailability of vitamin D in obesity. Am J Clin Nutr 72(3):690-693.

Wu H, Gozdzik A, Barta JL, Wagner D, Cole DE, Vieth R, Parra EJ \& Whiting SJ (2009). The development and evaluation of a food frequency questionnaire used in assessing vitamin $\mathrm{D}$ intake in a sample of healthy young Canadian adults of diverse ancestry. Nutr Res 29(4):255261.

Yaakob O \& Chau QP (2005). Weather downtime and its effect on fishing operation in Peninsular Malaysia. Jurnal Teknologi 42(A):13-26. 